Article

\title{
Major Improvements of Quartz Crystal Pulling Sensitivity and Linearity Using Series Reactance
}

\author{
Vojko Matko * and Riko Šafarič
}

University of Maribor, Faculty of Electrical Engineering and Computer Science, Smetanova 17, 2000 Maribor, Slovenia; E-Mail: riko.safaric@uni-mb.si

* Author to whom correspondence should be addressed; E-Mail: vojko.matko@uni-mb.si; Tel.: +386-2-220-7111; Fax: +386-2-220-7272.

Received: 16 July 2009; in revised form: 23 September 2009 / Accepted: 23 September 2009 / Published: 19 October 2009

\begin{abstract}
This paper presents a new method of substantially improving frequency pullability and linearity using reactance in series with an AT fundamental crystal operated with a series load capacitance in the range of 3 to $50 \mathrm{pF}$ and frequencies in the range of 3.5 to $21 \mathrm{MHz}$. The research describes high quartz pullability and linearity by varying the load capacitance. The paper also gives impedance circuits for crystal unit $(3.5 \mathrm{MHz})$ together with load capacitance and compensation reactance. The experimental results show that the new approach using compensation method of quartz crystal connected in series reactance increases the frequency pulling range by $\times 25$ to $\times 100$ depending on the type of oscillator and compensation factor " $\mathrm{k}$ " in the temperature range of 10 to $40{ }^{\circ} \mathrm{C}$.
\end{abstract}

Keywords: quartz crystal; pulling range; pulling linearity

\section{Introduction}

Quartz crystals are generally suited for the manufacture of frequency selection or frequency control devices. In oscillators with load capacitance in series with the crystal unit, the oscillation frequency depends on the capacitive load that is applied. The amount of nonlinear frequency change as a function of load capacitance is referred to as the pullability. It indicates how far from the nominal frequency (intended oscillating frequency) the resonant frequency can be forced by applying the load [1]. Typically, it is used to tune the operating frequency to a desired value. In special cases, it can also be used for the measurement purposes, allowing the measurement of various quantities based on 
capacitive influence on the quartz crystal oscillation frequency [2-3]. However, when these various quantities are measured, the problem of insufficient sensitivity and nonlinear characteristics very often arises.

This research focuses on the pulling sensitivity and linearity of the AT fundamental quartz crystals (cut angle: +2 ) operating over the measurement temperature range of 10 to $40{ }^{\circ} \mathrm{C}$. Crystals fabricated in this manner exhibit excellent frequency vs. temperature stability. They have fundamental resonant frequencies between 3.5 and $21 \mathrm{MHz}$.

\section{Compensation of $C_{0}$ and Pulling Sensitivity Improvement}

The equivalent circuit is an electrical representation of the quartz crystal's mechanical and electrical behaviour. The components $\mathrm{C}, \mathrm{L}$, and $\mathrm{R}$ are called the motional arm and represent the mechanical behaviour of the crystal element. $\mathrm{C}_{\mathrm{o}}$ represents the electrical behaviour of the crystal element and holder. Typical quartz data of $3.5 \mathrm{MHz}$ resonance frequency (fundamental mode) is as follows: $\mathrm{fr}=3.5 \mathrm{MHz}, \mathrm{C}=25 \mathrm{fF}, \mathrm{L}=82.8 \mathrm{mH}, \mathrm{R}=10 \Omega$ and $\mathrm{C}_{\mathrm{o}}=4 \mathrm{pF}$. The values in the quartz crystal equivalent circuit were measured by a HP 4194A impedance/gain-phase analyzer.

The capacitance $\mathrm{C}_{\mathrm{o}}$ is a real capacitance, comprising the capacitance between the electrodes and the stray capacitance associated with the mounting structure. It is also known as the "shunt" or "static" capacitance, and represents the crystal in a non-operational, or static state. Depending on the particular enclosure type, $\mathrm{C}_{\mathrm{o}}$ normally lies between 1 and $7 \mathrm{pF}$. Oscillator crystals are normally designed with $\mathrm{C}_{\mathrm{o}}$ less than $7 \mathrm{pF}$. One possibility how to increase the pulling sensitivity is to reduce $\mathrm{C}_{\mathrm{o}}$ in Equation 1, which is the serial resonant frequency for the crystal in series with load capacitence $C_{z}[1]$ :

$$
\mathrm{fs}(\mathrm{Cz}):=\frac{\sqrt{1+\frac{\mathrm{C}}{\mathrm{Co}+\mathrm{Cz}}}}{2 \cdot \pi \sqrt{\mathrm{L} \cdot \mathrm{C}}}
$$

The other possibility is to compensate $\mathrm{C}_{\mathrm{o}}$ with parallel inductance $\mathrm{L}_{\mathrm{p}}$ connected to basic quartz crystal equivalent circuit providing that $\omega_{0} \cdot L_{p}=1 /\left(\omega_{0} \cdot C_{o}\right)$, resulting in Equation 2 [4-7]:

$$
f s p(C z):=\frac{\sqrt{1+\frac{C}{C z}}}{2 \cdot \pi \sqrt{L \cdot C}}
$$

The novelty lies in the compensation of $C_{o}$ with inductance $L_{p w}$ providing that $\omega_{0} \cdot L_{p w}=1 /\left(\omega_{0} \cdot C_{0}\right)$ (Figure 1) with the criterion $\mathrm{k} \cdot \mathrm{L}_{\mathrm{pw}}=1 / \mathrm{k} \cdot \mathrm{C}_{\mathrm{o}}$. Resistance $\mathrm{R}_{\mathrm{pw}}$ is a real part of impedance $\mathrm{Z}_{\mathrm{pw}}$.

Figure 1. Load capacitance $C_{z}$ and compensation impedance $Z_{p w}=j \cdot \omega \cdot L_{p w}+R_{p w}$ in series with the quartz crystal equivalent circuit.

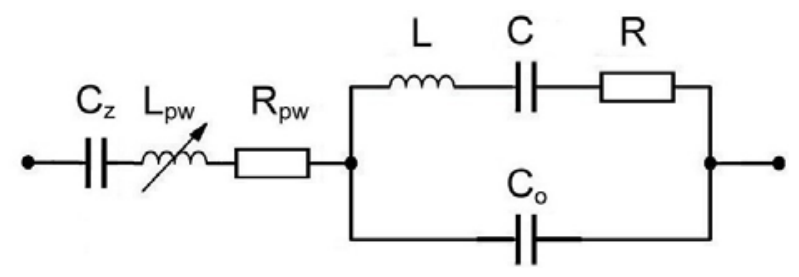


Figure 2 shows a comparison of the pulling sensitivity between Equations 1 and 2 for a $3.5 \mathrm{MHz}$ quartz crystal in the capacitance range of $3-50 \mathrm{pF}$. The change of frequency is approximately two times higher if we compensate $C_{o}$ [dependence $f_{s p}\left(C_{z}\right)$ ]. For the general sensitivity measurement purposes, the capacitance range between $3 \mathrm{pF}$ and $20 \mathrm{pF}$ is the most useful. It is in this range that the frequency capacitance dependence is the greatest (the highest pulling sensitivity). The highest frequency sensitivity is in the range $3-10 \mathrm{pF}$, where a very small capacitance changes can be measured (aF range). Figure 2 also shows typical nonlinear frequency dependence and a small pulling range $[\mathrm{dfs}(\mathrm{Cz}) \sim 40 \mathrm{kHz}]$.

Figure 2. Quartz crystal pulling sensitivity from 3 to $50 \mathrm{pF}$.

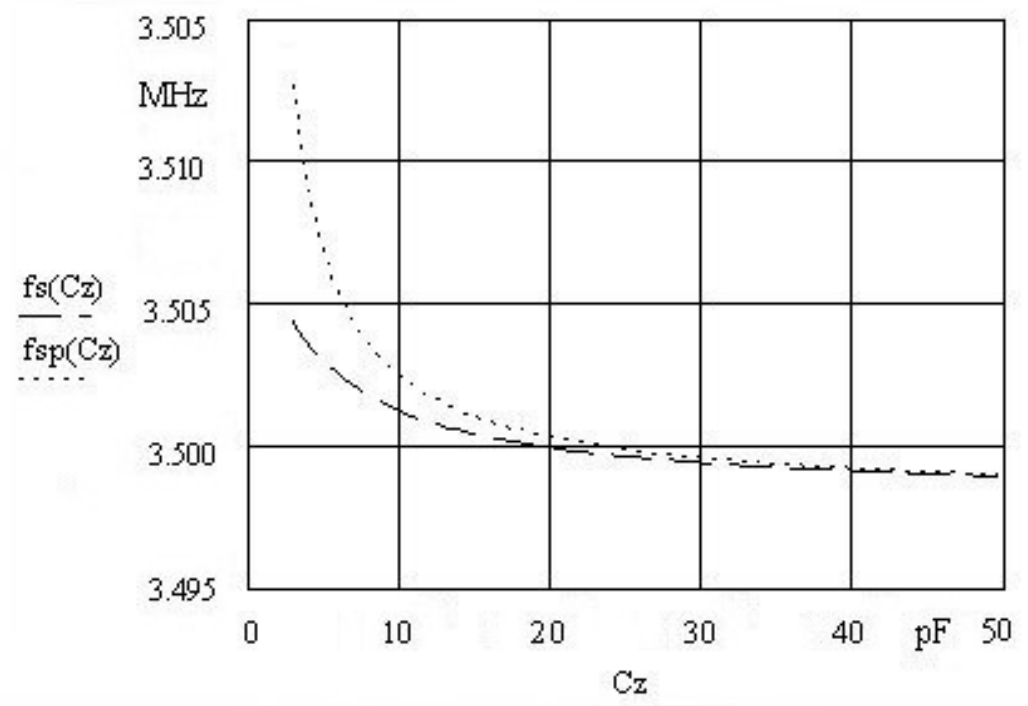

\section{The Use of Serial Reactance for Linearity and Pulling Sensitivity Improvement}

Taking into account that:

$$
\text { fr }:=\frac{1}{2 \cdot \pi \sqrt{\mathrm{L} \cdot \mathrm{C}}}
$$

where $-f_{r}$ is resonant frequency with phase 0 , and

$$
\omega_{0}:=2 \cdot \pi \cdot f_{\mathrm{r}}
$$

using the inductance $\mathrm{L}_{\mathrm{pw}}$ connected in series and providing that $\mathrm{k} \cdot \mathrm{L}_{\mathrm{pw}}=1 / \mathrm{k} \cdot \mathrm{C}_{\mathrm{o}}$ (Equation 5),

$$
\mathrm{Lpw}:=\frac{1}{\omega \mathrm{o}^{2} \cdot \mathrm{Co}}
$$

we get Equation 6, where we have a linearized frequency dependance with regard to $C_{z}$ for various $C_{o}$ values which change with " $k$ " values. This represents a novelty in this research. Due to very small inductance $\mathrm{L}_{\mathrm{pw}}$, the real resistance $\mathrm{R}_{\mathrm{pw}}$ can be ignored (Figure 1) [4]. 
$\mathrm{k}=1,2,3$

$$
\operatorname{fsk}(\mathrm{Cz}):=\frac{1+\frac{\mathrm{C}}{2 \cdot\left(\frac{1}{\mathrm{k}} \cdot \mathrm{Co}-\frac{1}{\omega 0^{2} \cdot \mathrm{k} \cdot \mathrm{Lpw}-\frac{1}{\mathrm{Cz}}}\right)}}{2 \cdot \pi \cdot \sqrt{\mathrm{L} \cdot \mathrm{C}}}
$$

Table 12 shows typical quartz data and experimental pulling results ( $\mathrm{dfs}$, dfsk for $\mathrm{k}=1$ and $\mathrm{k}=2$ ) for four different quartz crystals in the frequency range 3.5 to $21 \mathrm{MHz}$. The novelty here is in the pullability increase (dfsk) at values $\mathrm{k}=1$ in $\mathrm{k}=2$ (Equation 6), taking into account Equation 5. The values in the quartz crystal equivalent circuit were measured by the HP 4194A impedance/gain-phase analyzer.

Table 1. Quartz data and pulling sensitivity in frequency range $3.5 \mathrm{MHz}$ to $21 \mathrm{MHz}$.

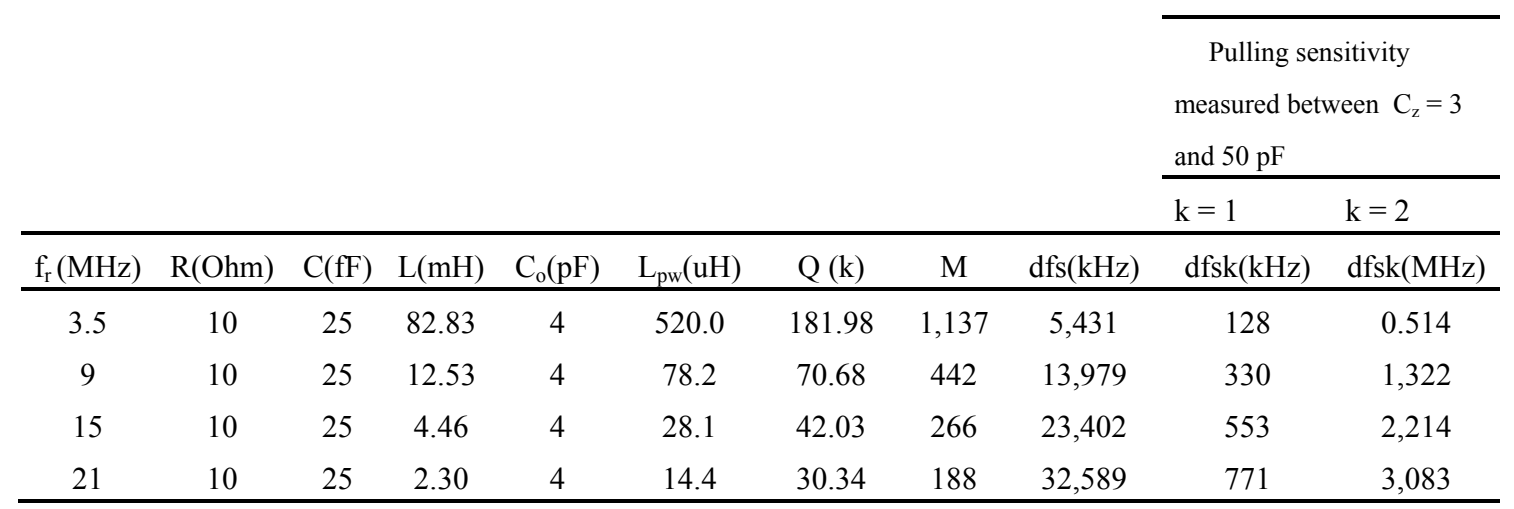

For the given various frequencies the quartz crystal data could also be different $\left(\mathrm{C}_{0}, \mathrm{C}, \mathrm{R}, \mathrm{L}\right)$. The frequency changes of dfs and dfsk (for $k=1$ and 2 ) are measured at various $C_{z}$ values $(3 \mathrm{pF}$ and $50 \mathrm{pF})$.

\section{Quartz Frequency Stability}

The maximum attainable stability of a crystal unit is dependent on the high $\mathrm{Q}$ value $(3.5 \mathrm{MHz}-$ Table 2). The smaller the distance between $f_{r}$ (series resonant frequency) and $f_{p}$ (parallel resonant frequency) the higher the $\mathrm{Q}$ value, and the steeper the slope of the reactance. The factors that further limit the Q are mounting loss, atmospheric loading (for non-evacuated crystal units) and the surface finish of the blank. Mounting loss depends upon the degree of trapping produced by the electrode and the plate diameter. The highest $\mathrm{Q}$ of quartz unit is important because of the frequency stability:

$$
\mathrm{Q}:=\frac{\omega \mathrm{O} \cdot \mathrm{L}}{\mathrm{R}}
$$

The figure of merit is a useful indicator, particularly for oscillator application and shows as the difference between $f_{r}$ and $f_{s}$ (pulling frequency difference value). In an oscillator, for a resonator with $M$ less than 2, the sustaining circuits must present inductive impedance to the crystal unit. As $M$ increases beyond $2, f_{r}$ and $f_{a}$ separate and, for large $M$, approach $f_{s}$ and $f_{p}$, respectively. In general, the larger $\mathrm{M}$ is the more useful resonator (the greater crystal oscillation stability):

$$
\mathrm{M}:=\frac{1}{\omega \mathrm{O} \cdot \mathrm{R} \cdot \mathrm{Co}}
$$


As a consequence of hysteresis, the frequency $v s$. temperature curves obtained by slowly increasing the temperature from, say, $10{ }^{\circ} \mathrm{C}$ to $40{ }^{\circ} \mathrm{C}$ will not coincide with the curve obtained by slowly decreasing the temperature from $40{ }^{\circ} \mathrm{C}$ to $10^{\circ} \mathrm{C}$. Frequency stability also depends on the temperature coefficient of the core material used of $\mathrm{L}_{\mathrm{pw}}$. The proper choice of the core material is also the key in the sense of the frequency stability.

In general, the oscillator's circuit long-term stability also depends upon the crystal aging. Cold weld packages which are specially processed and welded in a high vacuum offer much better ageing rates and typically the ageing rates of cold weld crystal is less than $\pm 1 \mathrm{ppm} / \mathrm{year}\left(10^{\circ} \mathrm{C}\right.$ to $\left.40{ }^{\circ} \mathrm{C}\right)$. Stability of the electronic circuit depends upon the circuit type and quality of its elements [8-11]. The frequency stability $\pm 0.1 \mathrm{~Hz}$ can be achieved provided that the above mentioned facts are taken into account and that the oscillator circuit is selected appropriately [1]. Another very important criterion for oscillator application is the drive level, which may not exceed $20 \mu \mathrm{W}$ [12].

\section{Experimental Results}

By satisfying the conditions of Equation 5, Equation 6 may be written, considerably increasing the frequency pulling range and linearizing it as shown in Figure 3 for the experimental data for the typical quartz data of $3.5 \mathrm{MHz}$ resonance frequency (fundamental mode).

Figure 3. Quartz crystal pulling and linearization for $k=1,2,3$ in the range $C_{z}=3-50 p F$.

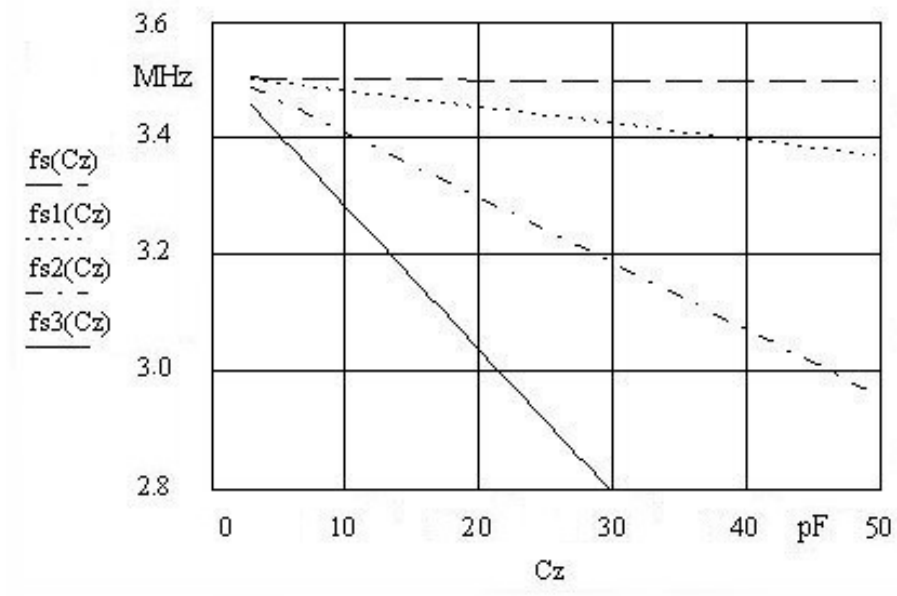

Figure 3 shows linear dependence for various $\mathrm{k}$ values as well as increased pulling (depending on the values of $C_{o}$ and $L_{p w}$ [Equation (6)] and also shows frequency dependences for serial resonant frequency $\mathrm{fs}\left(\mathrm{C}_{\mathrm{z}}\right)$ (without compensation), dependance of function $\mathrm{fs} 1\left(\mathrm{C}_{\mathrm{z}}\right)$ (with compensation) for $\mathrm{k}=1$, fs $2\left(\mathrm{C}_{\mathrm{z}}\right)$ for $\mathrm{k}=2$ and $\mathrm{fs} 3\left(\mathrm{C}_{\mathrm{z}}\right)$ for $\mathrm{k}=3$, and the last one being very hard to achieve due to a very small capacitance $\mathrm{C}_{\mathrm{o}} \cong 1.33 \mathrm{pF}$. The oscillator frequency measurement error is approximately $\pm 0.1 \mathrm{~Hz}[1]$.

We can define pulling sensitivity $\mathrm{S}$ as the frequency change in parts per million per $\mathrm{pF}$ change at a given load capacitance $\mathrm{C}_{\mathrm{z}}$ for various $\mathrm{k}$ :

$$
\underset{m}{S}:=\frac{C}{2 \cdot\left(\frac{1}{k} \mathrm{Co}+\mathrm{Cz}\right)^{2}}
$$


In such a way, we can determine " $\mathrm{S}$ " for 3 to $50 \mathrm{pF}$. Since $\mathrm{C}_{\mathrm{o}}$ and $\mathrm{C}$ are the same throughout our experiments (Table 1), we get the same "S" values for different k values (Table 3 ) for the frequencies 3.5 to $21 \mathrm{MHz}$ (Table 2).

Table 2. Quartz data and pulling sensitivity S.

\begin{tabular}{ccccccc}
\hline & $\mathbf{C}_{\mathbf{z}}=\mathbf{3} \mathbf{~ p F}$ & \multicolumn{5}{c}{$\mathbf{C}_{\mathbf{z}}=\mathbf{5 0} \mathbf{~ p F}$} \\
\hline & $\mathrm{k}=1$ & $\mathrm{k}=2$ & $\mathrm{k}=3$ & $\mathrm{k}=1$ & $\mathrm{k}=2$ & $\mathrm{k}=3$ \\
$\mathrm{~S}$ & $2.551 \times 10^{8}$ & $5 \times 10^{8}$ & $6.657 \times 10^{8}$ & $4.287 \times 10^{8}$ & $4.663 \times 10^{8}$ & $4.744 \times 10^{8}$ \\
\hline
\end{tabular}

If we define the frequency ratio $\Omega=\omega / \omega_{0}$, which depends on $\omega_{0}=1 / \sqrt{L \cdot C}$, and taking into account $\omega_{0} L=1 / \omega_{0} C$, the impedance equation for a crystal unit with $C_{z}$ and $L_{p w}$ is [1], [13]:

$\Omega=0.998,0.99802 \ldots 1.038$.

$$
\mathrm{Zk}(\Omega):=\left[\mathrm{R} \cdot \frac{1+\omega \mathrm{o} \cdot\left(\frac{\mathrm{L}}{\mathrm{R}}\right) \cdot\left(\Omega-\frac{1}{\Omega}\right) \cdot \mathrm{j}}{1+\frac{\mathrm{Co}}{\mathrm{k} \cdot \mathrm{C}} \cdot\left(1-\Omega^{2}\right)+\frac{\mathrm{Co}}{\mathrm{k} \cdot \mathrm{C}} \cdot \frac{\mathrm{R}}{\omega \mathrm{o} \cdot \mathrm{L}} \cdot \Omega \cdot \mathrm{j}}\right]+\left(\frac{\Omega \cdot 2 \cdot \pi \cdot \mathrm{k} \cdot \mathrm{Lpw} \cdot \mathrm{j}}{\sqrt{\mathrm{L} \cdot \mathrm{C}}}\right)+\mathrm{Rpw}+\frac{\sqrt{\mathrm{L} \cdot \mathrm{C}}}{\Omega \cdot 2 \cdot \pi \cdot \mathrm{Cz} \cdot \mathrm{j}}
$$

At the frequency of $3.5 \mathrm{MHz}$ and data for $\mathrm{C}_{\mathrm{z}}=3 \times 10^{-12}$ and $\mathrm{k}=1,2,3$ we get the three complex impedances as shown on Figure 4 (Equation 10). $\Omega$, representing the change of resonant frequency in the vicinity of the serial resonant frequency $f_{r}$ (the point where $\operatorname{Im}\left(Z_{k}\right)=0$ represents the series resonant frequency $\mathrm{f}_{\mathrm{r}}$ ). Figure 4 shows that by increasing the " $\mathrm{k}$ " values, $\operatorname{Im}\left(\mathrm{Z}_{\mathrm{k}}(\Omega)\right)$ and the pulling sensitivity of the quartz crystal increase as well as illustrated on Figure 3 (at value $\mathrm{k}=3$ the complex value of impedance $\operatorname{Im}(\mathrm{Zk} 3(\Omega))$ is doubled).

Figure 4. Compensated quartz impedance $\left(\mathrm{C}_{\mathrm{o}}\right)$ for different $\mathrm{k}=1,2,3(\Omega=0.998,0.99802 \ldots 1.038)$.

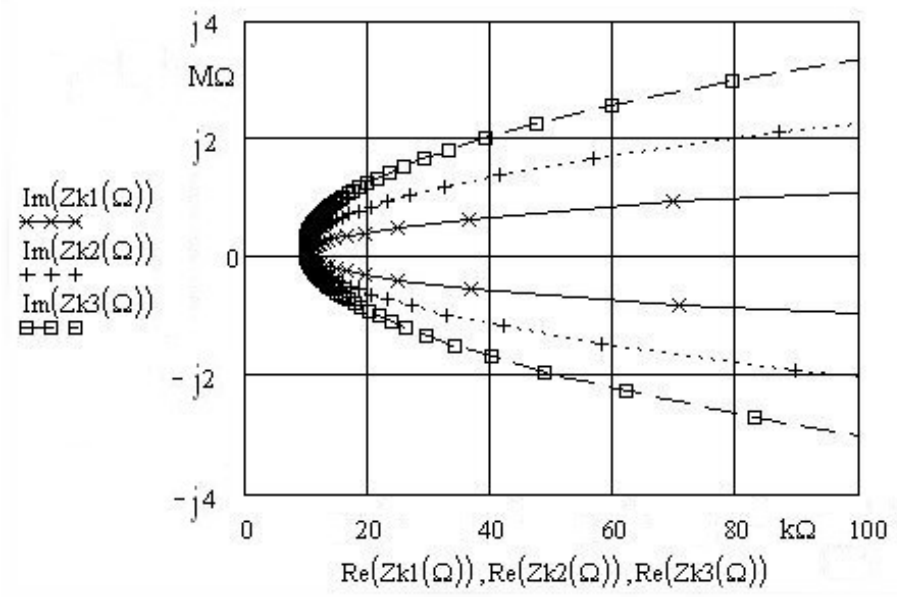

\section{Conclusions}

Experimental results of the comparison between compensated quartz crystal equivalent circuit and those using a non-compensated quartz crystal equivalent circuit show that the use of series reactance 
compensated crystals of the same frequency increases the pulling range by $\times 25$ for $\mathrm{k}=2$ and $\times 100$ for $\mathrm{k}=3$ also depending on the circuit used. It is the increase of pulling and a simultaneous linearilization that represents a novelty and a major advantage of this method in the measurement of femto and atofarad ranges. When the load capacitance is connected in series with the crystal, the frequency of operation of the oscillator is linearly increased inside limited values. It should also be emphasized that the exact pulling limits depend on the crystal's Q-value as well as associated stray capacitances. The most common factors affecting frequency stability such as operating temperature range, aging, hysteresis and drive level as well as all other crystal characteristics influencing the stability should also be considered because a stable oscillator circuit plays an important role in the increase of pulling and linear frequency dependance. Increased pulling range obtained experimentally can be used for determination of many different measurements such as strain, compression, positioning, angle, level, pressure, humidity, dielectric, biological growth, bacteria growth, and many other non-electrical quantities [14-16].

\section{References and Notes}

1. Matko, V. A comparison of frequency pullability in oscillators using a single at-cut quartz crystal and those using two single AT cut crystals connected in parallel with a series load capacitance or series load inductance. Sensors 2006, 6, 746-755.

2. Matko, V. Quartz sensor for water absorption measurement in glass-fiber resins. IEEE Trans. Instrum. Meas. 1998, 47, 1159-1162.

3. Matko, V. Determination of porosity using a water pycnometer with capacitive level detection. Sensor. Mater. 2004, 16, 1-12.

4. Jauch Q. Gmbh. Quartz crystal theory. Available online: http://www.jauch.de/ablage/ med_00000619_1193753698_Quartz\%20Crystal\%20Theory\%202007.pdf (accessed on September 28, 2009).

5. ATMEL. Analyzing the Behavior of an Oscillator and Ensuring Good Start-up. Available online: http://www.atmel.com/dyn/resources/prod_documents/doc4363.pdf (accessed on September 28, 2009).

6. Stanford Research Systems. Quartz Crystal Microbalance theory, Available online: http://www.thinksrs.com/ downloads/PDFs/ApplicationNotes/QCMTheoryapp.pdf (accessed on September 28, 2009).

7. Brice, J.C. Crystals for Quartz Resonators. Rev. Mod. Phys. 1985, 57, 105-138.

8. Euroquartz. Quartz Oscillator Theory. Available online: http://www.euroquartz.co.uk (accessed on September 28, 2009).

9. Interoperability and Performance Standards for Communications Timing and Synchronization Subsystems. Military Standard, MIL-STD-188-115; Department of Defense: , PA, USA, 1969; pp. 130-150.

10. Kusters, J.A.; Vig, J.R. Thermal Hysteresis in Quartz Resonators. In Proceedings of 44th Annual Symposium on Frequency Control, Baltimore, MD, USA, 1990; pp. 165-175.

11. Rutman, J.; Walls, F.L. Characterization of frequency stability in precision frequency sources. IEEE Trans. Instrum. Meas. 1991, 79, 952-960. 
12. Lap-Tech Inc. Standard Frequency Components. Available online: http://www.laptech.com/ (accessed on September 28, 2009).

13. Schrüfer, E. Electrical Measurement: Quartz as a Frequency Reference. Carl Hanser Verlag: München, Germany, 1992; pp. 405-412.

14. Miller, G.L.; Wagner, E.R. Resonant phase shift technique for the measurement of small changes in grounded capacitors. Rev. Sci. Instrum. 1990, 61, 1267.

15. Gotlih, K.; Troch, I. Base Invariance of the Manipulability Index. Robotica 2004, 22, 455-462.

16. Rajh, M.; Gotlih, K.; Kramberger, J.; Glodež, S. Improving haptic properties using manipulability visualization. Gép 2008, 58, 123-126.

(C) 2009 by the authors; licensee Molecular Diversity Preservation International, Basel, Switzerland. This article is an open-access article distributed under the terms and conditions of the Creative Commons Attribution license (http://creativecommons.org/licenses/by/3.0/). 